\title{
UN PROBLEMA SEMANTICO Y UN MITO PERSISTENTE: EL LIBRE FLUJO DE INFORMACION Y EL DERECHO A SABER
}

Todo el asunto del "libre flujo de noticias" ha pasado a ocupar un destacado sitial en las agendas de los simposios internacionales, así como en los documentos escritos que tratan aspectos de las comunicaciones mundiales. El término ha llegado a ser endémico en la retórica auspiciada por la UNESCO y en el diálogo entre el Tercer y el Primer Mundo. La mayor parte de las afirmaciones toma la forma de lamentaciones respecto del "triste estado" del flujo de las noticias entre las naciones y, especialmente, frente a la falta de equidad de tal flujo. El que las noticias sean dominadas por las naciones capitalistas del Primer Mundo es también tema central de las críticas.

En la medida que las naciones comunistas y aquellas en desarrollo se complacen en tales críticas, el Primer Mundo apenas reacciona a medias, y eso de un modo principalmente defensivo. Occidente, por ejemplo, no ha intentado demostrar el absurdo del llamado tercermundista en favor de un "flujo equilibrado de noticias", y tampoco ha cuestionado la premisa de que el "libre flujo" guarda relación, antes que nada, con la destrucción del dominio de las comunicaciones occidentales. Occidente tampoco ha recordado a los críticos que el libre flujo comienza dentro de un país -en la fuente misma de la noticia - donde realmente se origina una noticia: y ese aspecto del "flujo" no puede ser razonablemente endosado al Occidente.

Me gustaría afirmar que el asunto de "libre flujo de noticias" está (1) deficientemente investigado, (2) es confuso y se le entiende mal $-\mathrm{y}$ hasta llega a ser contradictorio en algunos de sus aspectos- (3) a menudo es empleado con fines propagandísticos por algunas naciones en sus ataques contra Occidente. Pero por sobre todo afirmaría que el así llamado problema es principalmente de índole semántica y no constituye en absoluto una "crisis", como ha afirmado UNESCO.

Las noticias fluyen hoy tan libremente como fluían en los tiempos en 
que comenzaron a intercambiarse noticias entre los países: con seguridad no es peor que hace 10, 20, 50 ó 100 años. Más aún, podría afirmarse con buena base que las noticias fluyen actualmente con mayor libertad que nunca antes, debido a la moderna tecnología, el siempre creciente número de periodistas en todo el mundo, la existencia de agencias noticiosas más grandes y más numerosas, además de otros factores.

Yo diría que la así llamada "crisis en el libre flujo de la información y las noticias" no es más que un mito. Calza decorosamente en el vasto paquete de la retórica antioccidental que proviene de muchos países del Tercer Mundo y de las conferencias y documentos de UNESCO. El hecho que las noticias fluyen de modo disparejo por el mundo y que determinadas naciones tienen una ventaja en este flujo refuerza otras críticas, como aquellas expresadas en términos de imperialismo occidental de las comunicaciones, prejuicios de los periodistas occidentales contra el Tercer Mundo, dominio tecnológico de Occidente, conversión de las noticias emanadas del Tercer Mundo en hechos sensacionalistas por parte de la prensa occidental, y otras cosas por el estilo.

La afirmación de que las noticias fluyen de modo desigual entre las naciones es efectivamente válida. Nadie sostiene que existe un equilibrio en el flujo mundial de noticias. El que las noticias no fluyan libremente también constituye verdad. Hay muchos factores - desde los secretos internos de los gobiernos y la manipulación de las noticias, hasta el desequilibrio tecnológico- que impiden que las noticias fluyan libremente. Pero tales factores son muchos y son universales y no pueden ser razonablemente endosados a las naciones capitalistas desarrolladas. La culpa de las restricciones al libre flujo de las noticias puede distribuirse entre varias fuentes.

Lo cierto es que sabemos muy poco en relación a la naturaleza y las características del flujo de noticias global. Sabemos algo en torno a él, desde luego, pero no contamos con antecedentes de investigación consistentes que revelen la característica básica de ese flujo, y, lo que es todavía más importante, casi no disponemos de estudios que expongan de modo sistemático la naturaleza de, el grado de, y las restricciones al desplazamiento real de las noticias e información alrededor del mundo. La mayor parte de las declaraciones que nos toca escuchar en esta área de diálogo están basadas principalmente en opiniones personales y poco más.

Ahora bien: ipor favor no se me malinterprete! Estoy consciente de que hay problemas en el área del flujo de la información y de las noticias. Siempre los ha habido. Siempre los habrá. Pero es ingenuo pensar que la información o las noticias pueden fluir en forma verdaderamente libre. Aquellos que sí lo creen no hacen frente a las realidades de la comunicación, de la economía, de la realidad política y social o de las desigualdades tecnológicas existentes en el mundo. Además no toman en cuenta el hecho de que algunas ciudades y naciones generan por causas naturales (y por tanto comunican) más "noticias" que otras ciudades y países. 
Debo admitir que el Dr. Wilbur Schramm tenía toda la razón cuando en su obra pionera de los años sesenta formuló algunas afirmaciones básicas que todavía son repetidas por profesores de comunicación y voceros de todo el mundo. Esas afirmaciones son:

1. Que el flujo de noticias entre las naciones es escaso;

2. que el flujo de noticias entre las naciones es desequilibrado;

3. que unas pocas naciones altamente desarrolladas logran una gran cobertura y que muchas naciones menos desarrolladas logran menor cobertura;

4. que el flujo de las noticias contribuye a la distorsión de la realidad que representa.

Estas son conclusiones con las cuales estarían en desacuerdo un número muy reducido de personas. Pero son más bien obvias e ignoran las sutilezas de la situación. ¡Claro que el flujo global total de noticias es "escaso"! ¡Claro que el flujo de noticias está desequilibrado! ¡Claro que algunos países logran una mayor cobertura que otros! ¡Y claro que el flujo de las noticias contribuye a la distorsión de la realidad! ¡Esa es la naturaleza de la comunicación! La comunicación es escasa en esencia, es desequilibrada en esencia, está prejuiciada en favor de algunos y en contra de otros. También está distorsionada. Eso es cierto tanto dentro de los países como entre los países.

Tal situación ha existido siempre, incluso antes de los días de la comunicación masiva. Siempre han sido unos pocos países o entidades los que han controlado el escenario de las comunicaciones mundiales: Egipto, Persia, Grecia, el Imperio Romano, Francia, Inglaterra, Alemania, Japón, los Estados Unidos, la Unión Soviética. Esas potencias han sido las generadoras de noticias, las diseminadoras de noticias, los centros de acción mundiales y regionales. Sólo es natural que sean o hayan sido puntos focales noticiosos en el mundo, tanto como fuentes de flujo de noticias y como objetivos de la cobertura noticiosa. Incluso dentro de ciertos países han sido determinadas ciudades las que han dominado el flujo de informaciones, las que han recibido una cobertura desproporcionada. Indudablemente ciudades como Roma, Londres, Berlín, París, Tokio, Moscú, Nueva York, Washington o Ciudad de México han dominado el flujo de noticias dentro de sus respectivos países. Eso constituye un fenómeno sólo natural y no es equivalente de conspiración. Lo que pretendo decir es simplemente lo siguiente: mientras más grande y más importante sean la ciudad o el país, tanto mayor cantidad de noticias producirán o generarán y tanto más atención hallarán en otras partes.

Esto constituye la ley o principio básico del "flujo de noticias".

Las noticias no son algo que sea generado y diseminado imparcial y equitativamente, ya sea dentro de los países o entre ellos. Y es bastante extraño que la UNESCO y los voceros del Tercer Mundo aparentemente 
que comenzaron a intercambiarse noticias entre los países; con seguridad no es peor que hace 10, 20, 50 ó 100 años. Más aún, podría afirmarse con buena base que las noticias fluyen actualmente con mayor libertad que nunca antes, debido a la moderna tecnología, el siempre creciente número de periodistas en todo el mundo, la existencia de agencias noticiosas más grandes y más numerosas, además de otros factores.

Yo diría que la así llamada "crisis en el libre flujo de la información y las noticias" no es más que un mito. Calza decorosamente en el vasto paquete de la retórica antioccidental que proviene de muchos países del Tercer Mundo y de las conferencias y documentos de UNESCO. El hecho que las noticias fluyen de modo disparejo por el mundo y que determinadas naciones tienen una ventaja en este flujo refuerza otras críticas, como aquellas expresadas en términos de imperialismo occidental de las comunicaciones, prejuicios de los periodistas occidentales contra el Tercer Mundo, dominio tecnológico de Occidente, conversión de las noticias emanadas del Tercer Mundo en hechos sensacionalistas por parte de la prensa occidental, y otras cosas por el estilo.

La afirmación de que las noticias fluyen de modo desigual entre las naciones es efectivamente válida. Nadie sostiene que existe un equilibrio en el flujo mundial de noticias. El que las noticias no fluyan libremente también constituye verdad. Hay muchos factores - desde los secretos internos de los gobiernos y la manipulación de las noticias, hasta el desequilibrio tecnológico- que impiden que las noticias fluyan libremente. Pero tales factores son muchos y son universales y no pueden ser razonablemente endosados a las naciones capitalistas desarrolladas. La culpa de las restricciones al libre flujo de las noticias puede distribuirse entre varias fuentes.

Lo cierto es que sabemos muy poco en relación a la naturaleza y las características del flujo de noticias global. Sabemos algo en torno a él, desde luego, pero no contamos con antecedentes de investigación consistentes que revelen la característica básica de ese flujo, y, lo que es todavía más importante, casi no disponemos de estudios que expongan de modo sistemático la naturaleza de, el grado de, y las restricciones al desplazamiento real de las noticias e información alrededor del mundo. La mayor parte de las declaraciones que nos toca escuchar en esta área de diálogo están basadas principalmente en opiniones personales y poco más.

Ahora bien: ¡por favor no se me malinterprete! Estoy consciente de que hay problemas en el área del flujo de la información y de las noticias. Siempre los ha habido. Siempre los habrá. Pero es ingenuo pensar que la información o las noticias pueden fluir en forma verdaderamente libre. Aquellos que sí lo creen no hacen frente a las realidades de la comunicación, de la economía, de la realidad política y social o de las desigualdades tecnológicas existentes en el mundo. Además no toman en cuenta el hecho de que algunas ciudades y naciones generan por causas naturales (y por tanto comunican) más "noticias" que otras ciudades y países. 
Debo admitir que el Dr. Wilbur Schramm tenía toda la razón cuando en su obra pionera de los años sesenta formuló algunas afirmaciones básicas que todavía son repetidas por profesores de comunicación y voceros de todo el mundo. Esas afirmaciones son:

1. Que el flujo de noticias entre las naciones es escaso;

2. que el flujo de noticias entre las naciones es desequilibrado;

3. que unas pocas naciones altamente desarrolladas logran una gran cobertura y que muchas naciones menos desarrolladas logran menor cobertura;

4. que el flujo de las noticias contribuye a la distorsión de la realidad que representa.

Estas son conclusiones con las cuales estarian en desacuerdo un número muy reducido de personas. Pero son más bien obvias e ignoran las sutilezas de la situación. ¡Claro que el flujo global total de noticias es "escaso"! ¡Claro que el flujo de noticias está desequilibrado! ¡Claro que algunos países logran una mayor cobertura que otros! ¡Y claro que el flujo de las noticias contribuye a la distorsión de la realidad! ¡Esa es la naturaleza de la comunicación! La comunicación es escasa en esencia, es desequilibrada en esencia, está prejuiciada en favor de algunos y en contra de otros. También está distorsionada. Eso es cierto tanto dentro de los países como entre los países.

Tal situación ha existido siempre, incluso antes de los días de la comunicación masiva. Siempre han sido unos pocos países o entidades los que han controlado el escenario de las comunicaciones mundiales: Egipto, Persia, Grecia, el Imperio Romano, Francia, Inglaterra, Alemania, Japón, los Estados Unidos, la Unión Soviética. Esas potencias han sido las generadoras de noticias, las diseminadoras de noticias, los centros de acción mundiales y regionales. Sólo es natural que sean o hayan sido puntos focales noticiosos en el mundo, tanto como fuentes de flujo de noticias y como objetivos de la cobertura noticiosa. Incluso dentro de ciertos países han sido determinadas ciudades las que han dominado el flujo de informaciones, las que han recibido una cobertura desproporcionada. Indudablemente ciudades como Roma, Londres, Berlín, París, Tokio, Moscú, Nueva York, Washington o Ciudad de México han dominado el flujo de noticias dentro de sus respectivos países. Eso constituye un fenómeno sólo natural y no es equivalente de conspiración. Lo que pretendo decir es simplemente lo siguiente: mientras más grande y más importante sean la ciudad o el país, tanto mayor cantidad de noticias producirán o generarán y tanto más atención hallarán en otras partes.

Esto constituye la ley o principio básico del "flujo de noticias".

Las noticias no son algo que sea generado y diseminado imparcial y equitativamente, ya sea dentro de los países o entre ellos. Y es bastante extraño que la UNESCO y los voceros del Tercer Mundo aparentemente 
piensen que el flujo de las noticias pueda ser "equilibrado". como ellos lo llaman.

Pero en realidad, este asunto del flujo equilibrado o parejo de las noticias es bastante diferente del asunto del libre flujo de las noticias, a pesar de la frecuencia con que se refiere a ellos como si fueran sinónimos. En efecto, si observamos este tema con seriedad, veremos que el "libre flujo" y el "flujo equilibrado" son conceptos realmente contradictorios. Cuando el flujo noticioso es libre, está destinado a ser desigual. La libertad de flujo - desde la fuente al receptor final- está condenada a producir desequilibrios en la cantidad de noticias que fluye. Un río de curso totalmente libre (sin represas o diques de origen humano, destinados a canalizar sus aguas) resultará en un flujo desigual: algunos puntos permanecerán secos y otros se verán inundados en la medida que el río siga libremente su curso natural. En pocas palabras, habrá un desequilibrio o desigualdad en el flujo de agua hacia diferentes áreas geográficas. La libertad opera de ese mismo modo. Sólo cuando la libertad es restringida, cuando las aguas (o la información) son controladas, puede establecerse algún tipo de igualdad o equilibrio.

Por tal motivo sostengo que si un país desea un flujo de noticias equilibrado, deberá insistir en un sistema controlado de su prensa, un sistema que asegure que cada ciudad y cada parte del país obtenga la misma cantidad y tipo de noticias. En otras palabras, si deseamos flujos noticiosos equilibrados, debemos establecer el control de la información. Si realmente deseamos un "libre flujo de noticias", habremos de oponernos a/y rechazar todo tipo de mecanismos que desvíe el flujo noticioso de sus canales naturalmente surgidos.

Otro principio básico del flujo noticioso es el siguiente: aquel gobierno que mantiene sus manos fuera de los medios de información realiza el mayor aporte al libre flujo de las noticias y de la información.

De modo que surge la siguiente pregunta: ¿aquellos países que exigen el "libre flujo", lo desean realmente? ¿O desean algún sistema que permita dirigir o administrar ese flujo de modo que calce con algún plan o modelo de flujo determinado?

En cuanto a las noticias concierne, el concepto de libre flujo arranca de la posibilidad de acceso de la prensa a las fuentes primarias de la noticia. Deben considerarse interrogantes como las siguientes: ¿Accede la prensa libremente a los líderes de los gobiernos? ¿Procede la información libremente del premier, presidente, rey o líder nacional? Si no ocurre así, entonces todo el concepto del "libre flujo" ya ha hecho un cortocircuito, y ciertamente no será culpa de algún villano extranjero como la norteamericana Associated Press o la británica agencia Reuter. No debemos olvidar que los problemas del libre flujo de las noticias generalmente comienzan en casa -al interior de los diversos países y no por obra y gracia de agentes externos.

Debiera considerarse todavía otra interrogante relacionada con el "li- 
bre flujo": ¿pueden las noticias fluir desinhibidamente de un país a otro? ¿Existe algún tipo de censura interna de las noticias procedentes de otro país? ¿Pueden, por ejemplo, fluir libremente en los Estados Unidos las noticias procedentes de la Unión Soviética? ¿Y pueden fluir libremente las noticias originadas en los Estados Unidos dentro de la Unión Soviética? Las restricciones al libre flujo de las noticias, debemos recordar, pueden hallarse tanto en el país de origen como en el país de destino. El acceso a las fuentes es el primer paso en el flujo de las noticias; el empleo de esas noticias y su recepción por el público constituyen el paso final.

Desde luego que el flujo de las noticias va más allá de las fronteras nacionales y de las restricciones internas. Incluye, en efecto, tareas tales como definición y selección de noticias, la atención de las agencias noticiosas a determinado tipo de noticias y problemas de transmisión. Y, por supuesto, ulteriormente también incluye el uso de la noticia que fluye.

A menudo he debido descubrir que mucha gente -incluyendo muchos profesores e investigadores - confunden el uso de las noticias con el flujo de las mismas. Esa gente concluirá que debido a que hay escasas noticias sobre México en los periódicos norteamericanos el flujo de noticias desde México a los Estados Unidos es pobre. Eso no es necesariamente cierto. La cantidad de noticias que "fluyen" es mucho mayor de las que se usan. Para estudiar el uso de las noticias debemos proceder a análisis de contenidos. Para estudiar el flujo de noticias, por otra parte, debemos estudiar los mecanismos de la diseminación internacional de las noticias, aislar los modelos de transmisión de noticias, y también debemos indagar qué cantidad de noticias se envía realmente de un país a otro y por cuáles medios se envían. El uso de las noticias puede constituir un aspecto del flujo de las noticias - el aspecto final - pero no puede en definitiva identificárselo con el flujo. Existe un error común: creer que porque pocos editores usaron reportajes procedentes de otro país en realidad no contaban con un acopio de reportajes sobre ese país. Sólo estudios sobre el flujo y estudios sobre la disponibilidad de noticias echarán luz sobre este importante asunto.

Los investigadores de las comunicaciones internacionales han sido rápidos en materia de iniciar estudios sobre "uso de noticias" (¿Cuántas y qué tipo de noticias sobre México usan los diarios norteamericanos?), pero han sido muy lerdos en materia de realizar estudios sistemáticos e intensivos sobre "flujo de noticias". ¿Cuántas y qué tipo de noticias sobre México son transmitidas desde México a los Estados Unidos y a través de qué medios? Bien, esto es una interrogante sobre "flujo de noticias" que es pocas veces analizada. Debemos forzosamente preocuparnos de este tipo de materias si deseamos obtener conclusiones creíbles y sustantivas sobre el "flujo de noticias" entre las naciones y la presencia o ausencia de una "crisis" en esta área.

¿Cómo podemos siquiera intentar decir que hay una "crisis" en el flujo de las noticias si carecemos de verdaderos antecedentes o pruebas en relación a la verdadera naturaleza del flujo de las noticias de país a país, de 
región a región? Insisto en que realmente no podemos, que hemos llegado a nuestras conclusiones a partir de una consideración del "uso" de las noticias, no del "flujo" de las mismas. Es tiempo de que modifiquemos nuestra retórica y comencemos a hablar de uso en lugar de flujo, o más bien es tiempo de que procedamos a realizar estudios sobre flujo de noticias a fin de cerciorarnos de cuál es la verdadera situación. En la actualidad realmente no lo sabemos.

La experiencia personal me ha demostrado que un editor de cables o de noticias extranjeras en los Estados Unidos a menudo obtiene cantidades sustanciales de noticias sobre otros países de la AP y de la UPI (así como de otras agencias y fuentes noticiosas) y que éstas terminan rápidamente en el canasto de los papeles. Esas noticias "fluyeron" hacia los Estados Unidos y hacia ese diario en particular, pero no fueron usadas. No fueron seleccionadas para su uso por el editor por uno u otro motivo. La noticia procedente del exterior debe competir con la noticia local y con una variedad de otros materiales editoriales. También debe competir con noticias procedentes de grandes ciudades occidentales y de "puntos calientes" de otras partes del mundo. El reportaje acerca de la nueva autopista o del nuevo puente inaugurado en Malawi, Perú o México simplemente no puede competir contra otras noticias en la mente de quien toma las decisiones en un diario norteamericano. No es que las noticias no hubieran fluido desde el otro país a los Estados Unidos, sino que simplemente no pudieron competir y no fueron usadas.

Tal es la naturaleza básica del periodismo. Al menos es la base natural del periodismo en una sociedad capitalista competitiva. Las noticias deben competir. Las noticias procedentes de determinado país en determinado momento simplemente son consideradas más importantes que aquellas procedentes de otro. Cierto tipo de noticias de esos mismos países son consideradas más importantes por los editores de noticias que otros tipos de noticias. Las noticias sobre México, por ejemplo, que pueda seleccionar un editor en un día dado, tal vez no sean lo que los editores o funcionarios del estado mexicano hubieran escogido; en opinión de los mexicanos tal vez no sean las noticias que entregan una imagen realista de México - pero son las noticias que son libremente seleccionadas por el editor periodístico sobre una base competitiva.

Este procedimiento simplemente constituye la naturaleza del periodismo en una sociedad capitalista. Y no hay nada que puedan hacer al respecto la UNESCO o cualquier grupo de críticos del Tercer Mundo. Organismos tales como la UNESCO pueden aprobar decenas de miles de resoluciones y declaraciones, pero ellas no surtirán el menor impacto sobre el principio periodístico básico de una selección independier e de las noticias por parte de quienes toman las decisiones editoriales en los medios de comunicación del Primer Mundo.

Podríamos triplicar el flujo de noticias procedentes de México, por ejemplo, sin alterar sustancialmente la cantidad de esas noticias finalmen- 
te usadas por los medios informativos. Esto constituye una afirmación hipotética, sin embargo, porque las realidades del periodismo probablemente imposibilitarían cualquier aumento de esa índole. En el periodismo norteamericano no existe una verdadera posibilidad de aumentar sustancialmente el uso de noticias mexicanas (o de las noticias de cualquier país) a menos que los editores periodísticos norteamericanos se convenzan de que existe una demanda de tales noticias por parte de sus lectores. La demanda determina el uso. $\mathrm{O}$, al menos, la supuesta demanda determina el uso. El flujo (la disponibilidad) de noticias desde otro país puede surtir cierto impacto sobre el uso de las mismas, pero este fenómeno debe verse acompañado de una convicción de los editores en el sentido de que los lectores desean esas noticias y las leerán. En otras palabras, las noticias del exterior deben competir con otro material editorial para su uso.

Ello significa que las noticias procedentes de determinados países (por ejemplo, El Salvador y Líbano en la actualidad) tendrán un flujo más intenso y serán más usadas que las noticias procedentes de otros países (por ejemplo, México y Liberia) que no se hallan en el centro focal en ese instante. Ese es el motivo por el cual un país como Israel recibe una atención desproporcionada de parte de la prensa mundial. Los países que generan noticias de interés y de importancia para la armonía o desarmonía del mundo generan mayor flujo de noticias y también logran mayor uso de parte de la prensa internacional. Es la importancia internacional intrínseca de las noticias (o lo que los periodistas estimen sea esa importancia) lo que afecta tanto su selección, formación y transmisión - su flujo-y ulteriormente su uso en los medios de comunicación social del mundo.

Los siguientes puntos, que constituyen un resumen concluyente, podrían servir como temas de discusión para aquellos de nosotros interesados en seguir todo el asunto del flujo de noticias y sus ramificaciones para la comunicación internacional y para todo el Nuevo Orden Informativo Mundial. Permítaseme exponer dichos puntos con un mínimo de comentarios y con el propósito de estimular mayor reflexión, estudio e investigación de los mismos:

- Todo el tópico del "libre flujo de noticias" está contrahecho por el "ruido" semántico que conduce a fricciones y malentendidos. Cabe realizar un verdadero esfuerzo destinado a conferirle precisión al concepto y aquellos que emplean el término no debieran por ahora asumir ninguna comprensión común del concepto.

- No hay una "crisis" en el flujo internacional de las noticias. Tal "crisis", de la cual tanto se habla, no es más que un mito. Hay un desequilibrio o falta de balance en el flujo noticioso, qué duda cabe, pero ello no es extraño. No hay todavía una investigación de peso que demuestre que tal desequilibrio perjudique una sustantiva armonía internacional $o$ amenace la paz mundial. 
- El "libre flujo de noticias" es contrario a un "flujo equilibrado de las noticias". Un flujo noticioso irrestricto y sin administrar naturalmente resulta en un desequilibrio del flujo. Si un gobierno desea equilibrio en el flujo noticioso tendrá que insistir en la dirección y administración de las noticias; no se podrá permitir un tipo de periodismo laissez-faire que resultaría en una especie de "periodismo de mercado" basado en fuerzas competitivas.

- Se necesita una mayor investigación del "flujo de noticias". Contamos con gran acopio de investigación de análisis de contenido —que pormenoriza la cantidad y naturaleza de las noticias que son usadas. Y ciertamente podemos suponer que sí existe un desequilibrio en el uso de las noticias en todo el orbe. $\mathrm{Y}$ ese tipo de investigación ciertamente es importante y debe ser continuada, pero lo que se requiere con mayor urgencia son estudios sobre "flujo de noticias" que echen luz sostenidamente sobre los moldes de origen-transmisión-recepción del flujo noticioso. Pues con seguridad fluye mayor cantidad de noticias de las que son usadas. El por qué los celadores de los medios informativos no usan mayor cantidad de esas noticias que fluyen es otra cuestión; también se requiere de más investigación sobre este aspecto.

- Las noticias deben competir por un espacio en los diarios capitalistas. Por tal razón cabe conjeturar que las noticias no serán las mismas para todos los países. Lo entregado a la publicidad es determinado principalmente por los periodistas que anticipan el interés de los lectores. De tal modo las noticias procedentes de ciertos países tendrán predominio en los medios informativos mundiales (por ejemplo, el Medio Oriente y América Central en 1984). Este "factor importancia" de las noticias de ciertos países impone barreras naturales contra todo el concepto de flujo noticioso equilibrado.

- El flujo de noticias no es lo mismo que el uso de las noticias. A pesar de que muchas veces se piensa que ambas cosas son idénticas, son bastante diferentes. Los profesores de comunicología y los investigadores debieran establecer un claro distingo entre ellos. El flujo de noticias en teoría siempre es mejor que su uso - aunque suele suponerse que "mientras más fluye, más se usa". Pero ello no necesariamente es así. Desafortunadamente muchos estudios de "uso" son malinterpretados por los docentes para evidenciar la naturaleza del "flujo" (las noticias que son en realidad transmitidas y recibidas). Pero deberá recordarse que un "uso" mínimo de noticias desde otros países no significa que de ellos "fluyan" pocas.

- El "flujo" de las noticias nunca será adecuado para algunas personas (y algunos países) - y aun si lo fueran, considerarían inadecuado el uso de las noticias. Los pueblos (y naciones) del mundo nunca estarán satisfechos 
con el flujo y uso de las noticias en la prensa. Esto opera del mismo modo en la esfera internacional como al interior de determinada nación. Este carácter "inadecuado" del flujo y del uso es intrínseco al periodismo. No hay realmente solución para este problema y debemos acostumbrarnos a su presencia.

\section{UN MITO PERSISTENTE: EL DERECHO A SABER}

Sigue sin abandonarnos una creencia generalizada en relación al llamado "derecho del público a saber", a pesar de que en los últimos 20 años y de tiempo en tiempo se han hecho sentir voces que desafían tal concepto del periodismo, especialmente en los Estados Unidos. Hace poco tuve la oportunidad de escuchar a cuatro destacados periodistas de televisión norteamericanos que sostenian un diálogo sobre el reporteo de las noticias. Cuando uno de los participantes mencionó el "derecho del público a saber" y la necesidad de la prensa de defender ese derecho, no hubo una sola voz en contra o que cuestionara el mencionado concepto.

Todo hace pensar que - al menos en el periodismo norteamericanoel concepto del derecho del público de saber se halla firmemente arraigado. $\mathrm{Y}$ aquellas personas que tienen un constante acceso a las ondas radiales y a los sistemas de TV de cable norteamericanos, así como a los medios de la prensa escrita, no permitirán que el concepto se esfume, sea cual fuere la opinión informada y el discurso lógico que se empleen para persuadirlos de lo contrario.

Personalmente me he interesado en diversos tipos de "derechos" de la gente desde fines de la Segunda Guerra Mundial y he quedado fascinado con la lista paulatinamente acumulada de tales "derechos" de las personas (que en ocasiones son representadas por individuos que se autodesignaron para ese fin). A comienzos de la década de los setenta comencé a alegar contra el concepto de "derecho del público a saber". Lo llamé uno de los mitos del periodismo norteamericano ${ }^{1}$. Naturalmente esta actitud no fue bien recibida por los periodistas - o, debo decirlo, por la mayor parte de mis colegas de la educación periodística-. Después de todo, tal "derecho" es habitualmente considerado como el principal cimiento funcional del "servicio público" ofrecido por el periodismo. La prensa se considera a sí misma como la institución que realiza (o intenta hacerlo) ese "derecho del público a saber". Y, por extrapolación, si el público tiene el derecho a saber, entonces se infiere que la prensa tiene el derecho de obtener la información con el fin de que el público pueda saber.

La mayor parte de los defensores de ese "derecho del público a saber" infiere ese supuesto derecho de la Primera Enmienda de la Constitución norteamericana. Pero, por supuesto, tal inferencia se encuentra totalmente en el área de la opinión, de la conjetura, de la presunción. Pues la Constitución de los Estados Unidos no dice una sola palabra (ni siquiera en su "Bill of Rights") respecto de cualquier derecho de las personas a saber. De 
acuerdo al profesor de Derecho de Harvard, Lawrence Tribe, uno de los principales constitucionalistas norteamericanos, existe una clara diferencia entre el "derecho a la palabra" y el "derecho del público a saber"'2. Otro importante estudioso de la Constitución norteamericana, Edwin Baker, está de acuerdo con lo planteado por Tribe, y señala que un "derecho a saber" no es nunca más que un derecho de que el gobierno no interfiera con "la libertad de un hablante voluntario"3.

¿Cuál es la razón principal de un derecho del público a saber? Los defensores de tal "derecho" señalan que los individuos en una sociedad libre debieran contar con la información que requieren tener. Si han de gobernarse a sí mismos, necesitarán información que les ayude en sus decisiones. El pragmatismo - y el pragmatismo en la autodeterminación - es el habitual motivo principal aducido para defender tal derecho. La gente "necesita" saber esto y aquéllo, y por tanto tiene el derecho a saber esto y aquéllo. Esa así llamada "necesidad" de saber (y esa necesidad es pragmáticamente determinada por los proveedores de información) ha sido así convertida en un "derecho a saber". Y, lo que resulta todavía más interesante, incluso la así llamada necesidad de saber se ha convertido - y en realidad se ha visto reducida - a nada más que un "deseo de saber" o en una "curiosidad de saber". E incluso ese deseo de saber es determinado por -o asumido por- la prensa y proyectado sobre las personas. De tal modo podemos ver cómo ese "derecho a saber" ha evolucionado en dirección de su tercera etapa de desarrollo: comenzó siendo una curiosidad por saber, que se convirtió en una necesidad de saber y esa necesidad pasó luego a constituirse en un derecho. Este concepto trinario o motivo principal para "conocer" explica los diferentes tipos de noticias que la prensa norteamericana ha reunido al alero del así llamado "derecho" a saber.

Por ejemplo, hay muchas noticias simplemente "curiosidadesorientadas", chismografía y cosas afines (del tipo del National Enquirer), que obviamente carecen de una verdadera importancia para el funcionamiento del gobierno o de la sociedad. Qué duda puede caber respecto de que no exista una verdadera necesidad de conocer buena parte de las "noticias" que obtenemos a diario. Luego tenemos noticias obviamente "útiles" y "convenientes" —noticias "útiles"— que el público sí tiene "necesidad" de conocer: información sobre elecciones, nuevas leyes, crisis de gobierno, amenaza de catástrofes naturales, etc. Y, enseguida, tenemos ese exhaustivo concepto de un "derecho a saber", que subsuma la curiosidad por saber y la necesidad de saber. La curiosidad y la necesidad han sidn elevadas al rango de "derecho". Y así están las cosas.

Lo que el periodista no dice es lo siguiente: lo que el público tiene derecho de saber es todo lo que los periodistas pueden obtener y que los periodistas piensan la gente debiera tener y que los periodistas estén dispuestos a entregar.

Este es un modo realista de poner las cosas, pero no un modo popular 
entre los hombre de prensa, puesto que los sitúa a ellos en el centro del círculo de responsabilidades. El periodista gusta de ver la responsabilidad por la gente colocada sobre los hombros de alguna otra institución o persona, no sobre la prensa o el periodista.

El periodista afirma que las personas tienen un derecho a saber, pero no entrega el nombre de sus fuentes de las personas.

El periodista afirma que las personas tienen un derecho a saber, pero procede a seleccionar cuidadosamente de sus notas ciertas informaciones para la gente y retiene para sí otro tipo de información.

El periodista afirma que las personas tienen un derecho a saber, pero se abstiene conscientemente de publicar ciertos reportajes o información que están en sus manos.

El periodista afirma que las personas tienen un derecho a saber, pero omite ciertos nombres en sus reportajes y decide entregar otros.

El periodista afirma que las personas tienen el derecho a saber, pero todos los días llena las cestas de papeles de la sala de prensa con reportajes e información que piensa el público no debiera (o no necesita) saber.

En pocas palabras, el periodista no cree genuinamente en el "derecho del público a saber", aunque lo proclama públicamente cada vez que se presenta la ocasión. En lo que sí cree el periodista es en el derecho del periodista de decidir lo que el público ha de saber. No pretendo aquí empequeñecer el concepto periodístico, pues es consecuente con el concepto de "autodeterminación editorial", con la tradicional libertad periodística, la libertad de los hombres de prensa de decidir qué publicarán y qué no.

Todo lo que pretendo decir aquí es que los periodistas no debieran hablar con una doble lengua. Ellos no pueden realmente creer en un "derecho del público a saber" cuando a la par ejercitan su propia libertad de prensa al determinar que el público obtendrá sólo cierta información.

En 1982, Kurt Luedtke, que ha sido periodista, editor y guionista cinematográfico, pronuncio un discurso ante la American Newspaper $\mathrm{Pu}$ blishers Association. Dijo clara y directamente - cosa que muy pocos periodistas hacen alguna vez-que:

"No existe nada semejante al derecho del público a saber. Ustedes acordaron eso teniendo cuidado de no especificar qué es lo que el público tiene derecho a saber. El público sabe lo que ustedes deciden decirle, ni más, ni menos. Si el público tuviera derecho a saber, realmente tendría algo que decir en relación a lo que ustedes eligen llamar noticias".

Luedtke lo dice bastante bien. Si el público realmente tiene un derecho a saber, con sẹguridad también tiene un derecho de determinar qué tipo de información realmente necesita saber y exigir que la prensa (como su representante) les entregue esa información sin tardanza. Como ha dicho Everette Dennis, si el público tiene tal derecho a saber, "hay que tirar por la 
ventana el derecho del editor y del radiodifusor de editar y decidir qué constituye una noticia". ${ }^{5}$ Dennis prosigue señalando:

"Si la prensa ha de convertirse en el representante legal del público bajo un principio general de un derecho a saber, entonces ciertamente las cortes y las legislaturas (estatales norteamericanas) le señalarán que tiene el deber de suministrar información particular al público. Ello en definitiva constituiría una chocante intromisión en la libertad de la prensa y es algo que espero ningún periodista pensante defendería"."

El concepto del derecho del público a saber ha sido promovido en los Estados Unidos especialmente a partir de la Segunda Guerra Mundial; libros tales como The Right to Know (1956) de Kent Cooper y The People's Right to Know (1953) de Harold Cross hicieron mucho por lanzar el concepto, y libros como Your Right to Know (1973) de Charles Whalen han seguide desarrollando la idea. A esto se suma que muchos artículos y discursos - $y$ mesas redondas televisadas - han mantenido el concepto arraigado en la mente pública.

Al escribir sobre este "derecho a saber" en 1974 (en The Imperative Freedom), personalmente sostuve que la mayoría de las noticias que evidenciaban una preocupación del público en torno a la parte jugada por el gobierno en mantener ciertas informaciones retenidas, exhibían, a su vez, una escasa preocupación por el papel de la prensa en mantener fuera del alcance del público determinadas informaciones (incluyendo información gubernamental). En realidad, cuando los periodistas se toman un tiempo para analizar verdaderamente este "derecho del público a saber", el concepto se evapora al ser puesto en contradicción con lo que constituye el orgullo y la alegría de los hombres de prensa: la libertad editorial.

Cuando uno piensa seriamente en torno de tal "derecho", siempre surge la siguiente interrogante: “¿Derecho a saber qué?” Y esto nos conduce a la pregunta siguiente: ¿Quién, entonces, decidirá qué es apropiado para que la gente lo sepa? Pues, tal como señalé en 1974, alguien o algún grupo debe decidir, dado que no se puede diseminar toda la información existente. Si ello resulta cierto, el concepto del "derecho del público a saber" se ve abreviado, pues ahora ya sólo significará el "derecho a saber" ciertas cosas que ciertas personas (los periodistas y sus fuentes) desean que sepamos. Esto, desde el punto de vista del público, constituye un "derecho" prácticamente insignificante y acentúa su "naturaleza mítica".

A pesar de que personas como Luedtke, Dennis y quien escribe tuvieron algo que decir en el pasado en relación al aspecto borroso - o tal vez la total inexistencia-de ese "derecho a saber", la mayoría de los que escriben o hablan (especialmente en el medio periodístico) sigue ensalzando ese "derecho" y fustigando al gobierno por restringirlo.

Sissela Bok, conocida redactora en el medio de la Universidad de Harvard y esposa del Presidente de la institución, lanzó un dardo mortal contra ese supuesto "derecho a saber" en fecha tan reciente como 1982. En 
su libro Secrets, alega poderosamente contra tal "derecho" en la meditia que analiza el carácter intrincado y excesivo del llamado "periodismo de: investigación". ${ }^{7}$ Señala la autora que, en los Estados Unidos, la noción de! "derecho del público a saber" se vincula estrechamente con la Primera Enmienda y su garantía de que, "el Congreso no dictará ley alguna... que restrinja la libertad de palabra, o de prensa"," y que esa garantía "presta dignidad y hasta carácter sagrado" a la función de la prensa; "para muchos periodistas — señala la autora - basta para justificar casi todo lo rue hacen". Pero, se pregunta la Bok, ¿cómo se conecta la Primera Enmienda con el derecho a saber del público $?^{3}$

Ronald Dworkin, citado por la autora, arguye que el derecho de palabra y el derecho a saber no son en absoluto la misma cosa y que por tal motivo la Primera Enmienda no garantiza en absoluto tal "derecho a saber". Señala. más adelante, que un "derecho de escuchar" (no un derecho a saber) seria $e l$ lazo conector adecuado con la libertad de expresión de la Constitución (de palabra y de prensa). Tal derecho de escuchar, señala Dworkin, es muy diferente del derecho a saber. La Corte Suprema de los Estados Unidos no ha reconocido un derecho a saber como un derecho constitucional. Nadie, señala Dworkin, podría demandar al "New York Times" por NO publicar los Papeles del Pentágono o ninguna otra cosa.

Es un tanto extraño que sea la propia prensa la que habitualmente defiende y perpetúa la idea de un "derecho a saber del público". Pues es la prensa la que debilita su propio concepto de "libertad" cuando plantea un derecho de las personas a saber. Tal derecho de las personas limita automáticamente la libertad de prensa: la libertad de retener informaciones y de insertar vacíos en los reportajes e información canalizados al público. Si la prensa realmente creyese en el derecho del público a saber, no podría retener, por ejemplo, el nombre de sus fuentes e informantes. Tampoco podría la prensa decidir no publicar los nombres de las víctimas de violaciones y una gran cantidad de otras informaciones que a menudo son importantes en un reportaje.

De modo que resulta paradojal el que sea la prensa que haga tanto alarde de un "derecho a saber" cuando es ella misma la que justamente mantiene constantemente al público lejos de saber determinadas cosas. Desde luego que la prensa intenta justificar su abstención de hacer saber todo al público con todo tipo de argumentos de carácter utilitario - señalando, por ejemplo, la necesidad de prevenir consecuencias perjudiciales, de no dañar la armonía pública o de proteger el interés nacional, etc. Pero, a la par, la prensa no siente simpatía por el gobierno cuando éste recurre a los nismos argumentos para intentar mantener cierta información fuera del alcance de la prensa (p. ej., la invasión de Grenada). Al parecer, la prensa gusta de emplear argumentos morales de propia creación para su propia renuencia a hacer saber al público, pero no está dispuesta a que el gobierno ( $u$ otras instituciones) emplee argumentos similares para mantener ciertas cosas fuera del conocimiento público. 
De modo que el mito persiste. Incluso periodistas veteranos y sofisticados, como Walter Cronkite, parecen considerar "el derecho del público a saber" y la "libertad de prensa" como sinónimos. Es indudable, la frase suena bien. La gente, la gente, la gente. Sus derechos, sus derechos, sus derechos. ¡Qué bien se oye! Pero una vez que las emociones se serenan, que la retórica se enfría y que los procesos del pensamiento gravitan hacia el análisis, el gran viejo mito pierde sus bríos y la realidad pasa a reemplazar a la mitología. Tal vez ello ocurra algún día también con "el derecho del público a saber". Aún así, ese mito parece todavía aferrarse tenazmente a la mente pública y no cabe olvidar que fue instalado allí y alimentado por los propios periodistas norteamericanos.

\section{NOTAS}

1 Jom C. Merkil.. The People's Right to Know Myth, New York State Bar Journal (noviembre de 1973). Cf. J.C. Merrill.

The Imperative of Freedom (Nueva York: Hastings House, 1974) véase especialmente, Cap. 5: "Tres mitos libertarios".

2 Lawrence H. Tribe, American Constitutional Law (Mineola, N.Y.: Foundation Press. 1978) véase esp. Cap. 12: "Communication and Expression", pp. 674.

3 Everette E. Dennis y John C. Merrill, Basic Issues in Mass Communication: A Debate (Nueva York: MacMillan, 1984), pp. 35

- Kurt LuedtKe. The Twin Perils: Arrogance and Irrelevance (Discurso pronunciado ante la Convención de la ANPA, San Francisco, 1982) en The Bulletin of ASNE (mayo-junio, 1982) pp. 4 - 5.

5 Dennis y Merrill, op. cit., pp. 37.

(5) Ibid.

7 Sissela Bo,, Secrets (Nueva York, Panteon Books, 1982) pp. 254-259.

B Ibid.

9 Ibid.

10 Ibid. pp. 225

Traducción de Martín Bruggendieck 